\title{
3-D Time-Accurate CFD Simulations of Wind Turbine Rotor Flow Fields
}

\author{
Nilay Sezer-Uzol* and Lyle N. Long ${ }^{\dagger}$ \\ The Pennsylvania State University, University Park, PA 16802
}

\begin{abstract}
This paper presents the results of three-dimensional and time-accurate Computational Fluid Dynamics (CFD) simulations of the flow field around the National Renewable Energy Laboratory (NREL) Phase VI horizontal axis wind turbine rotor. The 3-D, unsteady, parallel, finite volume flow solver, PUMA2, is used for the simulations. The solutions are obtained using unstructured moving grids rotating with the turbine blades. Three different flow cases with different wind speeds and wind yaw angles are investigated: $7 \mathrm{~m} / \mathrm{s}$ with $0^{\circ}$ yaw (pre-stall case $\mathrm{I}$ ), $7 \mathrm{~m} / \mathrm{s}$ with $30^{\circ}$ yaw (prestall, yawed case II), and $15 \mathrm{~m} / \mathrm{s}$ with $0^{\circ}$ yaw (post-stall case III). Results from the inviscid simulations for these three cases and comparisons with the experimental data are presented. Some information on the current work in progress towards Large Eddy Simulations (LES), including details about the viscous grid and the implementation of wall-functions, are also discussed. The inviscid results show that the flow is attached for cases I and II, with the latter having an asymmetrical wake structure, whereas there is massive separation over the entire blade span in case III. There are considerable spanwise pressure variations in addition to the chordwise variations, in all three cases. Comparisons of sectional pressure coefficient distributions with experimental data show good agreement. These threedimensional and time-accurate CFD results can be used for the far-field noise predictions based on the Ffowcs Williams - Hawkings method (FW$\mathbf{H})$, which can provide a first-principles prediction of both the noise and the underlying turbulent flow that generates the noise, in the context of the wind turbine application.
\end{abstract}

\section{Introduction}

Wind turbines offer the promise of inexpensive and clean energy, but the prediction of their aerodynamic and aeroacoustic properties is more challenging in many ways than that of already complicated problems such as helicopter rotors and propellers. In particular, wind turbine blades can experience large changes in angle of attack associated with sudden large gusts, changes in wind direction, atmospheric boundary layer effects or interaction

${ }^{*}$ Graduate student, Dept. of Aerospace Engineering, Email: nxs216@psu.edu, AIAA Student Member

${ }^{\dagger}$ Professor of Aerospace Engineering, Email: lnl@psu.edu, AIAA Fellow 
with the unsteady wake shed from the tower support on downwind, horizontal axis wind turbines. These blade/inflow/tower wake interactions can result in impulsive loading changes and dynamic stall over portions of the rotating blades. These influences are described in detail in several reports by the National Renewable Energy Laboratory (NREL) based on the NREL Unsteady Aerodynamics Experiments, such as Robinson et al. ${ }^{1}$ Furthermore, typically important rotor noise sources, such as steady thickness and loading noise, do not play the same role in large scale wind turbines, because the blade passage frequency is well below the audible range. Recognition of this fact leads one to consider rotor broadband noise sources as the primary noise source. Turbulence ingestion noise, airfoil self noise, tip-vortex noise, and other broadband noise sources have typically been treated through empirical or semi-empirical methods. ${ }^{2-6}$ In addition, the acceptance of wind turbines by the public depends strongly on achieving low noise levels in application.

Three-dimensional flow properties of rotating blades are an essential feature of any wind turbine aerodynamic or aeroacoustic simulation. While important information can be learned from two-dimensional and non-rotating simulations, some aspects of the physics of wind turbine aerodynamics and noise must be obtained from rotating blade simulations. Threedimensional flow over rotating blades can be significantly different than the flow over a wing, and there can also be dramatic differences between 2-D and 3-D simulations., 8 Rotating blades can have significant spanwise (or radial) flow. Also, of course, the blade speed varies linearly from root to tip. In addition, the three-dimensional wake of a rotating blade can remain in close proximity to the blade for a long period of time (compared to the wake of a wing). Furthermore, the acoustic propagation is of interest at relatively large distances from the wind turbine, and the far-field noise predictions based on the Ffowcs Williams Hawkings method $(\mathrm{FW}-\mathrm{H})^{9}$ could be used for this purpose. ${ }^{10}$

Using the time-dependent governing equations allows the simulation of a number of important phenomena: broadband noise, incoming atmospheric turbulence and gusts, wind shear (or atmospheric boundary layer). These are important for leading edge noise and tip noise prediction. By incorporating time dependent boundary conditions, either a gust or turbulent incoming flow can be introduced. Chyczewski et al. ${ }^{11}$ have done this in the past with jet noise predictions, to simulate turbulence levels inside the nozzle and their effect on the jet shear layers and noise.

For these reasons, time-accurate three-dimensional and compressible rotating blade simulations are essential. There have been several CFD studies of wind turbine flow fields using different approaches in the literature. ${ }^{12-16}$

This paper presents the results of three-dimensional and time-accurate CFD simulations of the flow field around 2-bladed NREL Phase VI wind turbine rotor. The solutions are obtained using the flow solver PUMA2 with unstructured moving grids rotating with the turbine blades. Three different flow cases with different wind speeds and wind yaw angles are investigated: $7 \mathrm{~m} / \mathrm{s}$ with $0^{\circ}$ yaw (pre-stall case I), $7 \mathrm{~m} / \mathrm{s}$ with $30^{\circ}$ yaw (pre-stall, yawed case II), and $15 \mathrm{~m} / \mathrm{s}$ with $0^{\circ}$ yaw (post-stall case III). Results from the inviscid simulations for these three cases and comparisons with the experimental data are presented. Some information on the current work in progress towards the LES runs, including details about the viscous grid and the implementation of wall-functions are also presented. 


\section{PUMA2 - Flow Solver}

PUMA2 uses a finite volume formulation of the Navier-Stokes equations for 3-D, compressible, unsteady or steady state solutions of problems for complex geometries. Mixed topology unstructured grids composed of tetrahedra, wedges, pyramids and hexahedra are supported in PUMA2. Several time integration and iterative algorithms such as RungeKutta, Jacobi and Successive Over-Relaxation Schemes (SOR) are implemented. The code is written in ANSI $\mathrm{C} / \mathrm{C}++$ using the MPI library for message passing so it can run on parallel computers and clusters. PUMA2 can be run so as to preserve time accuracy or as a pseudo-unsteady formulation to enhance convergence to steady state. It uses dynamic memory allocation, thus the problem size is limited only by the amount of memory available on the machine. Large Eddy Simulations (LES) ${ }^{17}$ with or without wall models ${ }^{18}$ can also be performed with PUMA2.

PUMA2 solves the steady/unsteady Euler/Navier-Stokes equations on unstructured stationary or moving grids. It has the capability to simulate time-accurate rotating blades through the use of additional metric terms in the equation that incorporate grid velocities into the flux terms. ${ }^{8}$ The flow field is solved directly in the inertial reference frame where the rotor blade and entire grid are in motion (i.e., rotation about an axis) at a specified rotational speed through any freestream. The solution at each time step is updated with an explicit algorithm that uses a 4-stage Runge-Kutta scheme. Therefore, the grid has to be moved four times per time step and it is required to recalculate only the grid velocities at each face center and the face normals for the specified grid motion at each time step.

The integral form of the Navier-Stokes equations incorporated in PUMA2 for Large Eddy Simulations are

$$
\begin{aligned}
& \frac{\partial}{\partial t} \int_{V} Q d V+\oint_{S}(\mathbf{F} \cdot \mathbf{n}) d S-\oint_{S}\left(\mathbf{F}_{\mathbf{v}} \cdot \mathbf{n}\right) d S=0 \\
& Q=\left\{\begin{array}{c}
\rho \\
\rho u_{1} \\
\rho u_{2} \\
\rho u_{3} \\
\rho e_{0}
\end{array}\right\}, \mathbf{F}_{j}=\left\{\begin{array}{c}
\rho\left(u_{j}-b_{j}\right) \\
\rho u_{1}\left(u_{j}-b_{j}\right)+p \delta_{1 j} \\
\rho u_{2}\left(u_{j}-b_{j}\right)+p \delta_{2 j} \\
\rho u_{3}\left(u_{j}-b_{j}\right)+p \delta_{3 j} \\
\rho h_{0}\left(u_{j}-b_{j}\right)+p b_{j}
\end{array}\right\}, \mathbf{F}_{\mathbf{v} j}=\left\{\begin{array}{c}
0 \\
\tau_{1 j}-\tau_{1 j}^{\prime \prime} \\
\tau_{2 j}-\tau_{2 j}^{\prime \prime} \\
\tau_{3 j}-\tau_{3 j}^{\prime \prime} \\
\left(u_{1} \tau_{1 j}+u_{2} \tau_{2 j}+u_{3} \tau_{3 j}\right)-q_{j}-\Theta_{j}^{\prime \prime}
\end{array}\right\} \\
& \tau_{i j}=2 \mu S_{i j}+\lambda \frac{\partial u_{k}}{\partial x_{k}} I_{i j} \\
& q_{j}=-k \frac{\partial T}{\partial x_{j}} \\
& \Theta_{j}^{\prime \prime}=\left(u_{1} \tau_{1 j}^{\prime \prime}+u_{2} \tau_{2 j}^{\prime \prime}+u_{3} \tau_{3 j}^{\prime \prime}\right)-q_{j}^{\prime \prime}
\end{aligned}
$$

where, $Q$ is a column vector of the flow variables in a conservative form. The index $i, j=$ $1,2,3$ refers to the components in each coordinate direction. $\mathbf{F}$ is the inviscid flux vector including pressure variations. In addition, $\mathbf{F}$ contains the effect of the moving body, through the body/grid velocity $\mathbf{b}\left(b_{1}, b_{2}, b_{3}\right)$, while the $\mathbf{U}\left(u_{1}, u_{2}, u_{3}\right)$ is the absolute flow velocity with respect to the inertial reference frame. $\mathbf{F}_{v}$ is the viscous flux vector which also includes the effects of the unresolved scales represented through the additional terms. $\tau_{i j}$ and $q_{j}$ 
are the viscous stress tensor and the heat flux vector, respectively. $\mu$ is the coefficient of dynamic viscosity, $\lambda$ is the second coefficient of viscosity, and $\mathrm{k}$ is the coefficient of thermal conductivity. $\tau_{i j}^{\prime \prime}$ and $q_{j}^{\prime \prime}$ are the residual, or the subgrid-scale (SGS), stresses and heat fluxes that need to be modelled, respectively. Pressure, total energy and total enthalpy are given by

$$
p=(\gamma-1) \rho e, \quad e_{0}=e+\frac{1}{2} \mathbf{U} \cdot \mathbf{U}, \quad h_{0}=e_{0}+\frac{p}{\rho}
$$

The classical Smagorinsky model ${ }^{19}$ is integrated into PUMA. Using the Smagorinsky model, which is an eddy-viscosity model, the SGS stresses and the eddy viscosity are defined as

$$
\begin{gathered}
\tau_{i j}^{\prime \prime}=-2 \mu_{t} S_{i j} \\
\mu_{t}=\left(C_{S} \Delta\right)^{2} \rho \sqrt{2 S_{i j} S_{i j}},
\end{gathered}
$$

where $C_{S}$ is the Smagorinsky constant and is typically assigned a value of 0.1 to 0.25 . The resolved strain-rate tensor is defined by:

$$
S_{i j}=\frac{1}{2}\left(\frac{\partial u_{i}}{\partial x_{j}}+\frac{\partial u_{j}}{\partial x_{i}}\right)
$$

The model for the SGS heat fluxes is:

$$
q_{j}^{\prime \prime}=\frac{\gamma R}{\gamma-1} \frac{\mu_{t}}{P r_{t}} \frac{\partial T}{\partial x_{j}}
$$

where $\mathrm{Pr}_{t}$ is the turbulent Prandtl number and is commonly chosen in the range of 0.3 - 0.5.

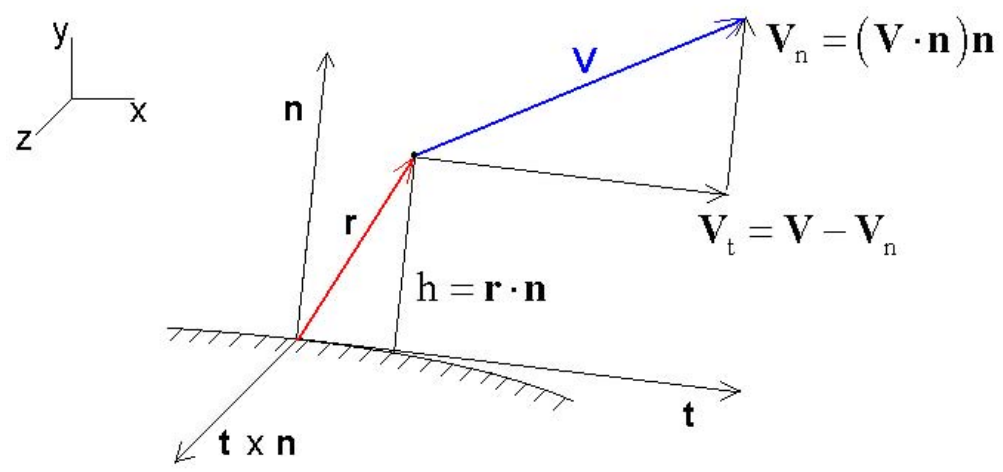

Figure 1. Velocity components at the first cell center away from the wall

A wall model based on an instantaneous logarithmic law of the wall is developed and implemented in PUMA2. ${ }^{18}$ For high Reynolds number turbulent flows the log-law approach is used at the first cell away from the solid surface to get the shear stress at the wall. The logarithmic law of the wall, which is obtained by neglecting all terms in the streamwise momentum equation except the Reynolds-stress gradient, can be expressed as:

$$
u^{+}=\frac{\left\|V_{\text {tangential }}\right\|}{u_{\tau}}=\frac{1}{\kappa} \log \left(y^{+}\right)+B .
$$


where, $y^{+}=h u_{\tau} / \nu$ is the distance to the wall in viscous units, and $\nu$ is the kinematic viscosity. From experiments for a flat plate at higher Reynolds number, the constants $\kappa$ and $\mathrm{B}$ are determined to be 0.41 and 5.0 respectively. The profile given in the equation is solved by Newton's method to obtain the frictional velocity $u_{\tau}$ which is then used to calculate shear stress as

$$
\tau_{w}=u_{\tau}^{2} \rho
$$

In the coordinate system of tangential velocity, normal velocity, and their cross product (see Figure 1) the wall shear stress tensor $\tau_{m n}$ can then be written as:

$$
\left(\begin{array}{ccc}
0 & \tau_{w} & 0 \\
\tau_{w} & 0 & 0 \\
0 & 0 & 0
\end{array}\right)
$$

The wall shear stress tensor is then transformed to the original $\mathrm{x}, \mathrm{y}, \mathrm{z}$ coordinate system using the orthogonal transformation.

$$
\tau_{i j}=C^{T} \cdot \tau_{m n} \cdot C
$$

where the rotation matrix $\mathrm{C}$ is defined by,

$$
\left(\begin{array}{ccc}
e_{\text {tangent }}[i] & e_{\text {tangent }}[j] & e_{\text {tangent }}[k] \\
e_{\text {normal }}[i] & e_{\text {normal }}[j] & e_{\text {normal }}[k] \\
e_{\text {cross }}[i] & e_{\text {cross }}[j] & e_{\text {cross }}[k]
\end{array}\right)
$$

where $e_{\text {tangent }}, e_{\text {normal }}$ and $e_{\text {cross }}$ are unit normal vectors in the tangential velocity, normal velocity and their cross product directions respectively. These shear stress components are then fed back to the outer LES model in the form of proper momentum flux at the wall.

The application of the instantaneous log-law wall model, without considering whether the flow is reversed or not, improved the skin friction predictions qualitatively according to the LES simulations of the flow around sphere at high Reynolds numbers. ${ }^{18}$

For the inviscid simulations $\mathbf{F}_{\mathbf{v}}$ is identically zero.

\section{Computational Test Cases}

In accordance with the NREL Unsteady Aerodynamics Experiments, ${ }^{20,21}$ in which largescale horizontal axis wind turbines were examined at the NASA Ames wind tunnel facilities, the two-bladed NREL Phase VI wind turbine (baseline) rotor has been considered for the CFD simulations. Blades have the NREL S809 airfoil section from root to tip. Pitch is defined at $75 \%$ span and the pitch axis is at the $30 \%$ chord line. A linearly tapered and nonlinearly twisted blade geometry with a span of $5.029 \mathrm{~m}$ and a flat tip, as shown in Figure 2, was generated using ProDesktop. Figure 3 shows the blade twist distribution and planform. ${ }^{20}$ The blade geometry used has $0^{\circ}$ twist at $75 \%$ span (and $-2^{\circ}$ twist at the tip). The blade has the root chord of $0.737 \mathrm{~m}$ and tip chord of $0.356 \mathrm{~m}$ with a taper ratio of ' $2.1^{\text {'. }}$ There is a cylinder with $0.109 \mathrm{~m}$ radius which extends from $0.508 \mathrm{~m}$ to $0.724 \mathrm{~m}$, and then there is a transition from the circular section at $0.724 \mathrm{~m}$ to the root airfoil section at radius $1.257 \mathrm{~m}$. 
In the NREL Phase VI experiments, the spherical-tip 5-hole probe shown in Figure 4 provided dynamic pressure, local flow angle, and spanwise flow angle measurements ahead of the blade at a distance of $80 \%$ chord at five span locations, $34 \%, 51 \%, 67 \%, 84 \%$, and $91 \%$ span. The probes were positioned at an angle nominally $20^{\circ}$ below the chord line to align the probe with the flow under normal operating conditions. In addition, chordwise blade surface pressure distributions are also measured at five spanwise stations: 30\%, 46.6\%, $63.3 \%, 80 \%$, and $95 \%$ span. Table 1 shows the selected experimental cases that may be used for validation and comparison of the computational test cases. Following these experiments, the computational cases are selected as shown in Table 2 . The rotor blades have $5^{\circ}$ pitch angle (at $75 \%$ span) and $0^{\circ}$ cone angle for the computational cases considered.

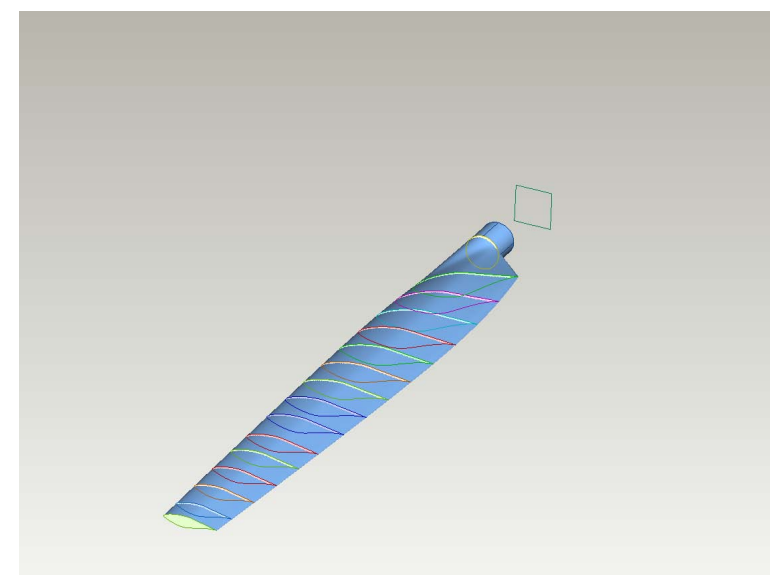

Figure 2. Three-dimensional NREL wind turbine blade geometry generated using ProDesktop.

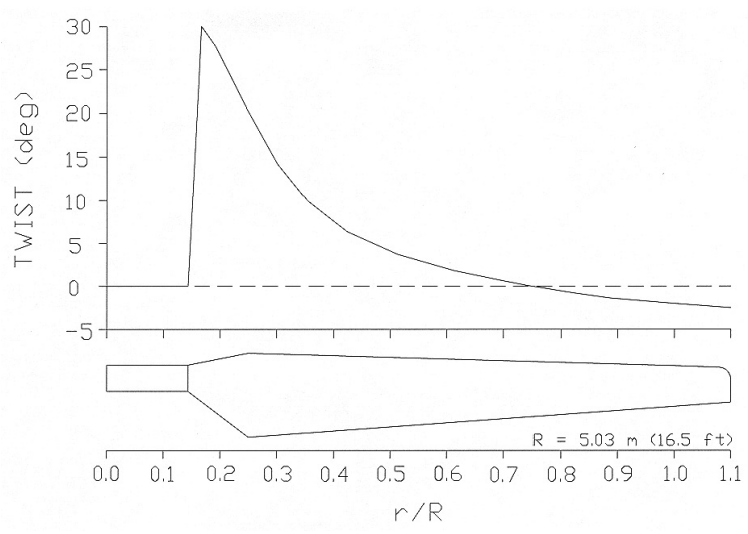

Figure 3. NREL wind turbine rotor blade twist distribution and planform. ${ }^{20}$

\section{A. Unstructured Grids}

An unstructured inviscid grid shown in Figures 5 and 6 with 3.6 million tetrahedral cells clustered around the blades and tip vortices was created with Gridgen software. Figure 6 shows the outer boundary, the mesh near the blade surface and the mesh on $x=0$ and $y=0$ planes. Through the use of unstructured grids, it is possible to heavily cluster points in regions of interest, while keeping the far-field cells rather coarse. 


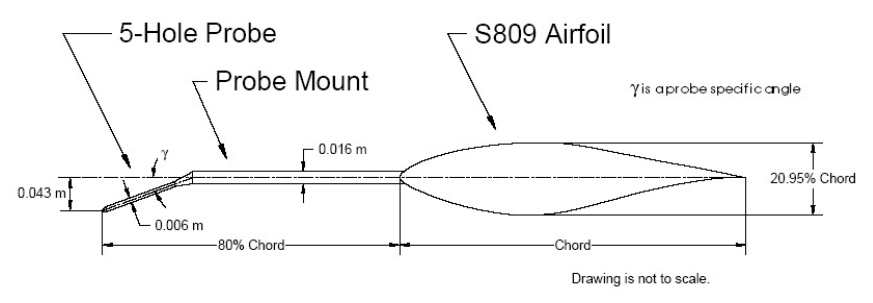

Figure 4. Blade-mounted five-hole probe used in NREL Phase VI experiments. ${ }^{21}$

\begin{tabular}{|l|l|l|}
\hline \multicolumn{1}{|c|}{ Test Matrix } & \multicolumn{1}{c|}{ Wind speed } & \multicolumn{1}{c|}{ Yaw angle } \\
\hline $\begin{array}{l}\text { H: Upwind } \\
\text { baseline case }\end{array}$ & $\begin{array}{l}7 \mathrm{~m} / \mathrm{s} \text { (pre-stall) } \\
10 \mathrm{~m} / \mathrm{s} \text { (onset of stall) } \\
15 \mathrm{~m} / \mathrm{s} \text { (post stall) }\end{array}$ & $\begin{array}{l}\text {-30, 0, 30, and } \\
60 \text { degrees }\end{array}$ \\
\hline $\begin{array}{l}P: \text { Wake flow } \\
\text { visualization }\end{array}$ & $5,7,10,15 \mathrm{~m} / \mathrm{s}$ & $\begin{array}{l}0,-10,-30,-60 \\
\text { degrees }\end{array}$ \\
\hline $\begin{array}{l}\text { 5: Sweep } \text { wind } \\
\text { speed case }\end{array}$ & $\begin{array}{l}5 \text { to } 25 \mathrm{~m} / \mathrm{s} \\
25 \text { to } 5 \mathrm{~m} / \mathrm{s}\end{array}$ & degrees \\
\hline
\end{tabular}

Table 1. Selected NREL Phase VI experimental $\operatorname{cases}^{21}$

The cylindrical computational domain has a radius of $12.0 \mathrm{~m}$ (about the height of turbine tower, i.e. $12.192 \mathrm{~m}$ ), which extends 4 and 2 rotor radii in positive (downstream) and negative (upstream) y-direction, respectively. For the two-bladed wind turbine rotor, the blade at 12 o'clock position (azimuth angle $=0^{\circ}$ ) is designated as Blade 2, and the Blade 1 is at 6 o'clock position, to be consistent with the NREL wind turbine experiments (Figure 7). The definitions of the yaw and the azimuth angles used in the computations are also shown in that figure. The blades rotate about the y-axis, in the negative direction with $72 \mathrm{rpm}$ $(7.54 \mathrm{rad} / \mathrm{sec})$. Wind speed in the positive $\mathrm{y}$-direction with different yaw angles has been considered for the test computations as seen in Figure 8. According to this figure, the relative angles of attack (flow angle with respect to the x-axis) of the wind at $80 \%$ span are calculated as $12.99^{\circ}, 10.16^{\circ}$ and $26.31^{\circ}$ for cases I, II and III, respectively.

The permeable FW-H surface (for noise calculations) was also embedded in the grid system as seen in Figure 9 during the grid generation process. This ensures that data can easily be extracted for noise computations.

An unstructured viscous grid in Figure 10 with 9.6 million tetrahedral cells clustered around the blades and tip vortices was created with Gridgen software for LES simulations. The minimum cell length for this grid is about $0.0001 \mathrm{~m}$. This grid has finer, clustered cell distribution around the blade compared to the inviscid grid in Figure 6.

\begin{tabular}{|l|l|l|}
\hline \multicolumn{1}{|c|}{ Test Cases } & \multicolumn{1}{c|}{ Wind speed } & \multicolumn{1}{c|}{ Yaw angle } \\
\hline$C A S E I$ & $7 \mathrm{~m} / \mathrm{s}$ (pre-stall) & 0 degrees \\
\hline$C A S E I I$ & $7 \mathrm{~m} / \mathrm{s}$ (pre-stall) & 30 degrees \\
\hline$C A S E I I I$ & $15 \mathrm{~m} / \mathrm{s}$ (post stall) & 0 degrees \\
\hline
\end{tabular}

Table 2. Selected computational test cases 


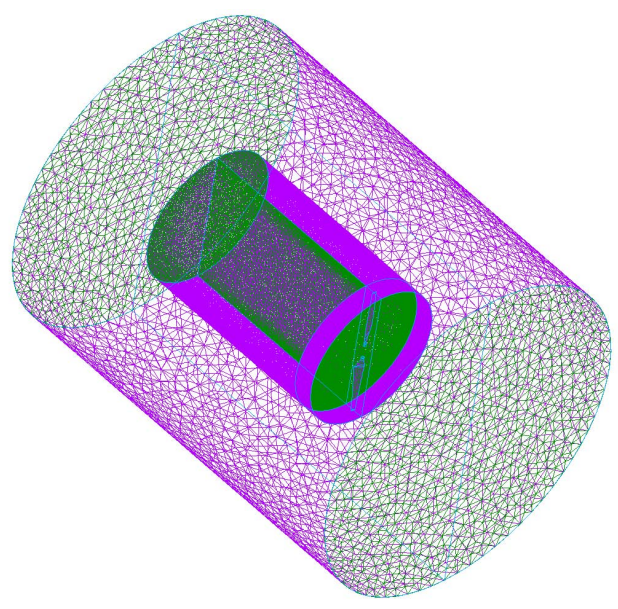

Figure 5. Unstructured tetrahedral grid generated using Gridgen.

\section{B. Parallel Computers and Computational Cost}

While many different approaches to programming parallel computers have been proposed over the years, the dominant approach today is to use Fortran or $\mathrm{C} / \mathrm{C}++$ with the messagepassing interface (MPI). This approach is fairly straightforward for regular grids using domain decomposition, but is more difficult for unstructured grids or implicit codes.

Computational tests and the selected cases were run mainly on the Penn State clusters, Lion-xl and Mufasa, (also some on the NREL, NCSA and NASA clusters). Table 3 summarizes the maximum number of compute nodes available, the processor speed, memory and the network connection characteristics of these clusters. Different numbers of processors were used to better characterize the computational resource requirements and potential throughput on each machine. Table 4 shows the computational performance of PUMA2 inviscid computations on different clusters, such as the memory required per compute node, and the number of days required for the computation of one complete revolution of wind turbine rotor for different numbers of processors. The wall time required per iteration versus number of processors is also plotted in Figure 11.

\section{Inviscid CFD Results}

The inviscid, time-accurate CFD simulations were performed for the NREL Phase VI turbine rotor using the flow solver PUMA2 with moving grids for three selected computational cases (See Table 2). The 4-stage Runge-Kutta numerical time integration method and Roe's numerical flux scheme was used in the computations. Time-accurate computations were started from the freestream conditions (for a given wind speed). Because the time step for time-accurate computations using an explicit scheme is determined by the smallest cell in the volume grid, the minimum cell size and maximum number of cells were selected during the grid generation process by also considering the total computational time needed for the time-accurate simulations. The simulation time step size was selected as 9.26 micro-second so that the calculated a Courant-Friedrichs-Lewy (CFL) number will be less than 1.0 for the smallest cell size $(0.0033 \mathrm{~m})$ in the volume grid. Parallel computations were performed on different Beowulf-clusters as explained in the previous section. The computations for one 


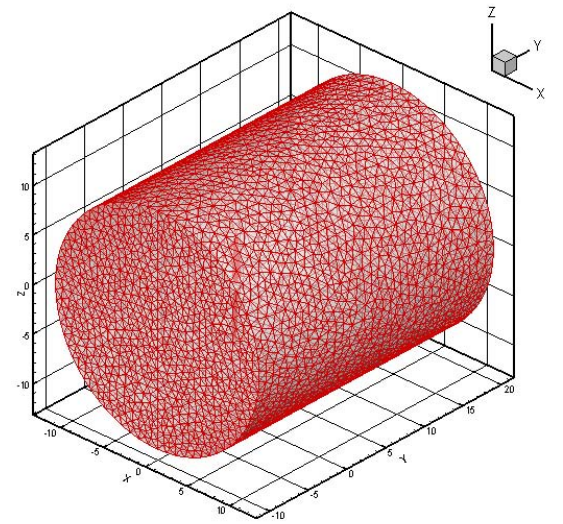

a) Cylindrical computational domain

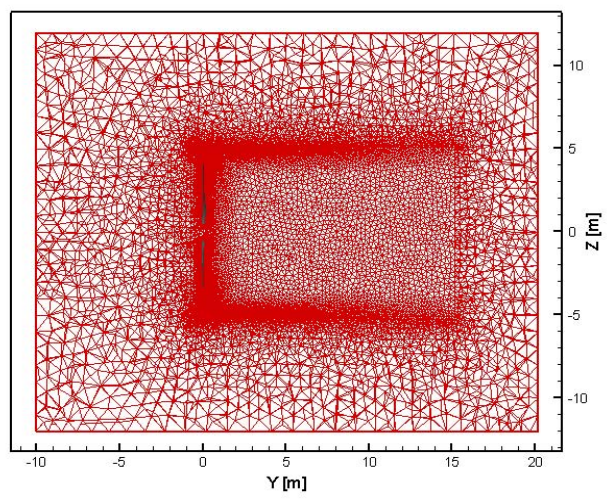

c) Mesh on $X=0$ plane

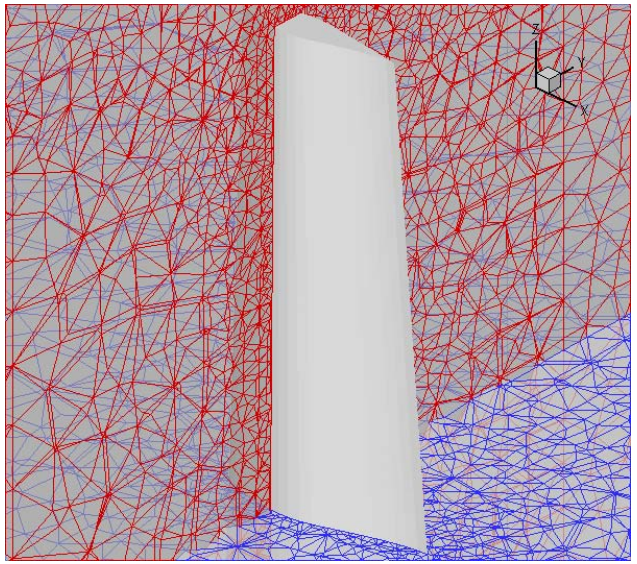

b) Grid near the blade surface.

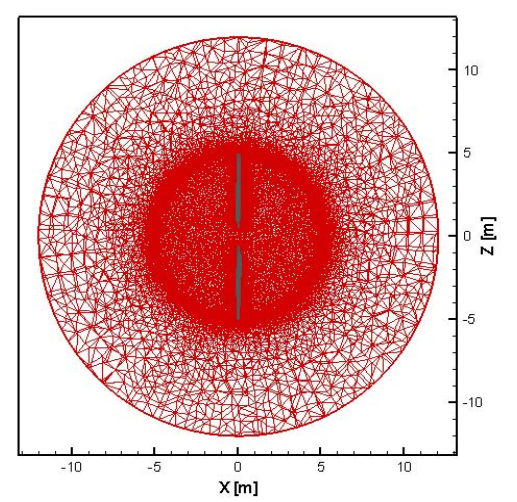

d) Mesh on $Y=0$ plane

Figure 6. Unstructured tetrahedral grid for inviscid computations.

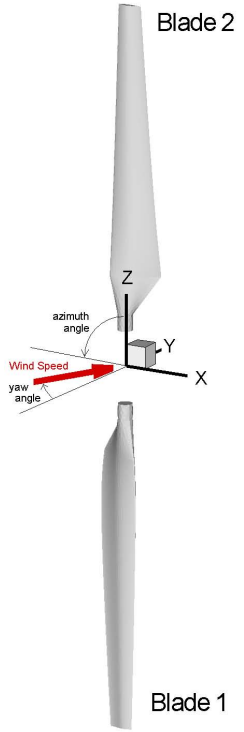

Figure 7. Two bladed wind turbine rotor.

\section{9 of 23}




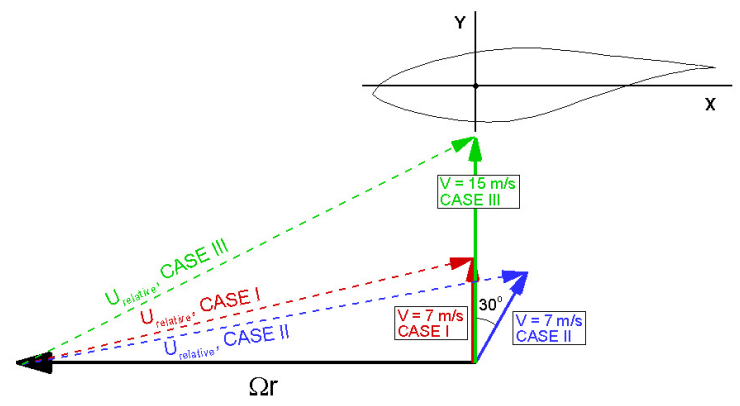

Figure 8. Velocity vectors for the wind and the rotating blade at $80 \%$ span for the selected computational cases.
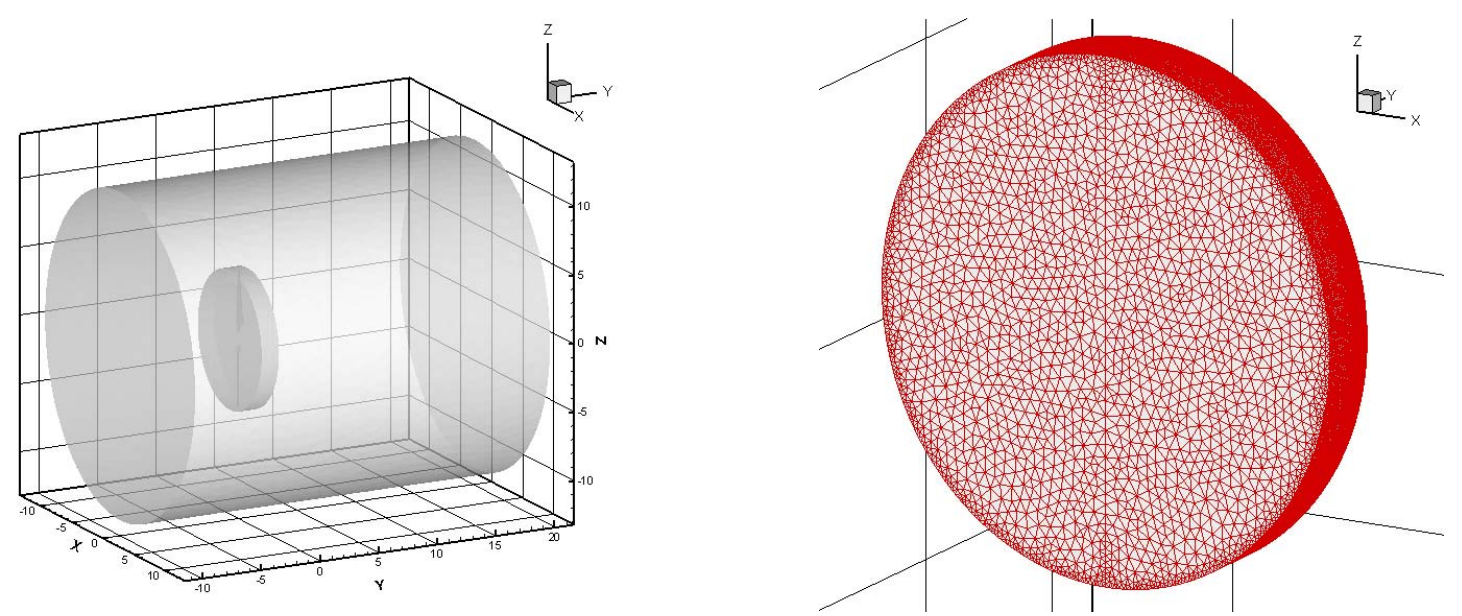

Figure 9. Permeable surface embedded in the unstructured grid.

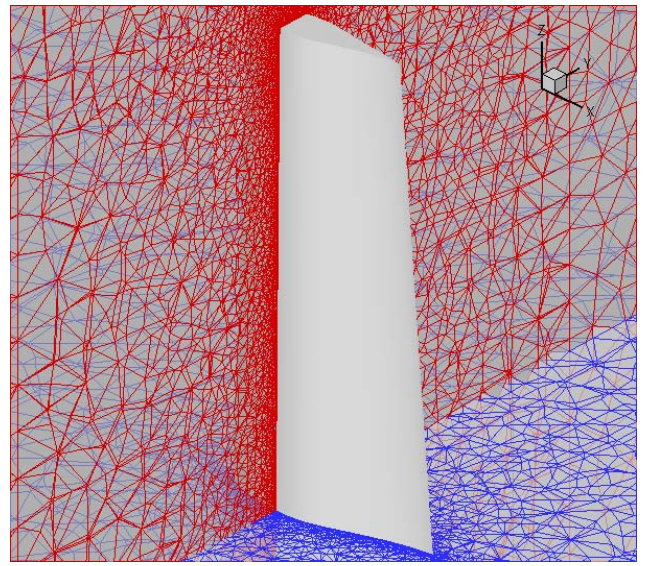

Figure 10. Unstructured tetrahedral grid for LES computations. 


\begin{tabular}{|c|c|c|c|c|}
\hline & $\begin{array}{c}\text { \# of compute } \\
\text { nodes }\end{array}$ & processors & memory & network \\
\hline $\begin{array}{c}\text { PSU } \\
\text { Lion-xl }\end{array}$ & 128 & $\begin{array}{c}\text { Dual } 2.4 \mathrm{GHz} \text { Intel } \\
\text { P4 }\end{array}$ & $\begin{array}{l}4 \mathrm{~GB} \text { of } \mathrm{ECC} \\
\text { RAM }\end{array}$ & $\begin{array}{l}\text { Quadrics high-speed } \\
\text { interconnect }\end{array}$ \\
\hline $\begin{array}{c}\text { PSU } \\
\text { Lion-xo }\end{array}$ & 168 & $\begin{array}{c}\text { Dual } 3.06 \mathrm{GHz} \\
\text { Intel Xeon } \\
\text { or Dual } 3.2 \mathrm{Ghz} \\
\text { Intel Xeon } \\
\end{array}$ & $\begin{array}{l}4 \mathrm{~GB} \text { of } \mathrm{ECC} \\
\text { RAM }\end{array}$ & $\begin{array}{c}\text { High Speed Myrinet } \\
\text { Network }\end{array}$ \\
\hline $\begin{array}{c}\text { PSU } \\
\text { Lion-xm }\end{array}$ & 168 & $\begin{array}{c}\text { Dual } 3.06 \mathrm{GHz} \\
\text { Intel Xeon } \\
\text { or Dual } 3.2 \mathrm{Ghz} \\
\text { Intel Xeon } \\
\end{array}$ & $\begin{array}{l}4 \mathrm{~GB} \text { of ECC } \\
\text { RAM }\end{array}$ & $\begin{array}{c}\text { High Speed Myrinet } \\
\text { Network }\end{array}$ \\
\hline $\begin{array}{c}\text { PSU } \\
\text { Mufasa }\end{array}$ & 81 & $\begin{array}{l}\text { Dual } 2.8 \mathrm{GHz} \\
\text { AMD Athlon } \\
\text { MP2200+ }\end{array}$ & $\begin{array}{l}2 \text { GB Memory } \\
\text { (10 nodes) \& } \\
1 \text { GB Memory } \\
\text { ( } 71 \text { nodes), }\end{array}$ & $\begin{array}{l}\text { Dolphin and fast } \\
\text { ethernet networks }\end{array}$ \\
\hline $\begin{array}{l}\text { NREL } \\
\text { Lester }\end{array}$ & $\begin{array}{l}\mathrm{STD}=56 \\
\mathrm{HSN}=40\end{array}$ & $\begin{array}{l}\text { Dual } 1.8 \mathrm{GHz} \\
\text { AMD Opteron }\end{array}$ & 4 GB memory & $\begin{array}{c}\text { STD }=\text { Gigabit Ethernet } \\
(50 \mathrm{MB} / \mathrm{s}) \\
\text { HSN }=\text { Dual Port } \\
\text { Myrinet }(800 \mathrm{MB} / \mathrm{s})\end{array}$ \\
\hline $\begin{array}{c}\text { NCSA } \\
\text { Tungsten }\end{array}$ & 1280 & $\begin{array}{c}\text { Dual } 3.2 \mathrm{GHz} \text { Intel } \\
\text { Xeon }\end{array}$ & $\begin{array}{l}3 \text { GB ECC DDR } \\
\text { SDRAM memory }\end{array}$ & $\begin{array}{c}\text { Gigabit Ethernet and } \\
\text { Myrinet } 2000\end{array}$ \\
\hline $\begin{array}{c}\text { NAS } \\
\text { Columbia }\end{array}$ & $\begin{array}{l}20 \text { SGI Altix } \\
3700 \\
\text { superclusters, } \\
\text { each with } 512 \\
\text { processors, }\end{array}$ & $\begin{array}{l}\text { Dual } 1.5 \mathrm{GHz} \text { Intel } \\
\text { Itanium } 2\end{array}$ & $\begin{array}{c}\text { Global shared } \\
\text { memory across } \\
512 \text { processors, } \\
1 \text { terabyte of } \\
\text { memory per } 512 \\
\text { processors }\end{array}$ & $\begin{array}{l}\text { Interconnect } \\
\text { SGI® NUMAlink }{ }^{\mathrm{TM}} \\
\text { InfiniBand network } \\
10 \text { gigabit Ethernet } \\
1 \text { gigabit Ethernet }\end{array}$ \\
\hline
\end{tabular}

Table 3. Characteristics of the several parallel computers used in the computations

\begin{tabular}{|c|c|c|c|c|c|c|}
\cline { 3 - 7 } \multicolumn{2}{c|}{} & \multicolumn{5}{c|}{ wall time required per revolution [days] } \\
\hline $\begin{array}{c}\text { \# of } \\
\text { processors }\end{array}$ & $\begin{array}{c}\text { memory/ } \\
\text { node } \\
{[\text { MB] }}\end{array}$ & Lion-xl & Mufasa & $\begin{array}{c}\text { NREL } \\
\text { cluster } \\
\text { Std }\end{array}$ & $\begin{array}{c}\text { NCSA } \\
\text { cluster }\end{array}$ & $\begin{array}{c}\text { NASA } \\
\text { cluster }\end{array}$ \\
\hline 16 & 297 & 14 & 42 & 15 & 10 & 11 \\
\hline 32 & 192 & 6 & 12 & 10 & 5 & 5.4 \\
\hline 64 & 140 & - & 8 & - & 2.4 & 3.5 \\
\hline 128 & 113 & - & 5 & - & 1.7 & 1.8 \\
\hline
\end{tabular}

Table 4. Computational performance of PUMA2 inviscid computations on different clusters 


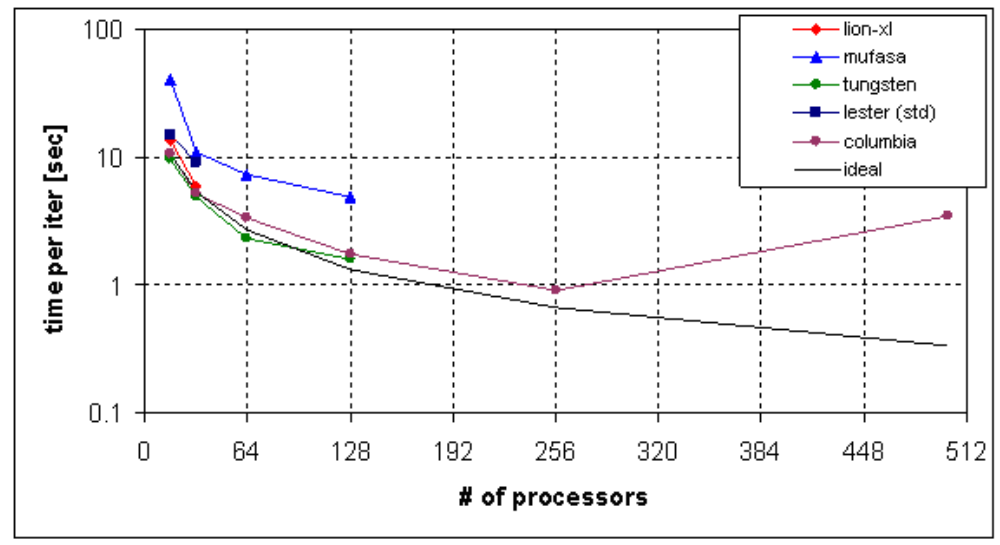

Figure 11. Computational performance of PUMA2 inviscid computations on different clusters

full revolution (i.e. 0.8333 seconds) require 90000 iterations.

The time accurate flow solution was stored every $30^{\circ}$ of rotor azimuth angle in the 1 st and 2nd revolution computations for all three cases. The solutions are stored every $1^{\circ}$ interval in the 3rd revolution for cases II and III, to be used for the aeroacoustic calculations.

The instantaneous vorticity iso-surfaces, which are obtained with a new utility code written for PUMA2, are shown in Figure 12. Several observations can be made. First, for case I, the flow is attached (as will be shown later in Figure 19), and well defined vortical structures are shed from the blade tips. For case II, the flow is again attached, however the wake is asymmetrical because of the $30^{\circ}$ yaw angle. For the higher wind speed case, i.e. case III, the flow is massively separated over the entire blade span. Although the tip vortices can still be depicted, the flow is highly unsteady because of the separation. This is much better observed when time-accurate results are visualized as an animation. In addition, the wake structures get convected at a higher speed compared to cases I and II. The vortical wake of case I is plotted at the end of 2 nd revolution, and it is expected that it will continue to develop as the computation is continued for more revolutions. However, the vortices are diffused for cases II and III as shown in Figure 12. This may be due to the grid quality and numerical dissipation which need to be studied further. Also, the grid used for all three cases was created considering the $0^{\circ}$ yaw cases (see Figure 6 ), so it may not be the best choice for the yawed case II which has an unsymmetric skewed wake structure.

The instantaneous pressure contours on the rotor blade upper and lower surfaces for all three cases can be seen in Figures 13, 14, and 15 for both blades 1 and 2. The contours show considerable spanwise pressure variations in addition to the chordwise variations. Figure 16 shows the instantaneous and averaged chordwise pressure coefficient distributions of the inviscid CFD simulations at 30\%, 46.6\%, 63.3\%, 80\% and 95\% spanwise stations for blade 2. The pressure coefficient is calculated using

$$
C_{P}=\left(P-P_{\infty}\right) /\left(\frac{1}{2} \rho_{\infty}\left[U_{\infty}^{2}+(\Omega \mathbf{r})^{2}\right]\right)
$$

where, $U_{\infty}$ is equal to $7 \mathrm{~m} / \mathrm{s}$ for cases I and II, and $15 \mathrm{~m} / \mathrm{s}$ for case III. The instantaneous distributions show the time-accurate CFD solutions at time $t=1.667 \mathrm{sec}$ (i.e. at the end of second revolution) for case $\mathrm{I}$, and at $\mathrm{t}=2.500 \mathrm{sec}$ (i.e. at the end of third revolution) for cases II and III. The averaged distributions are obtained by averaging the solutions with $30^{\circ}$ 
intervals over the 2 nd revolution for case I, and by averaging the solutions with $1^{\circ}$ intervals over the 3rd revolution for cases II and III. In Figure 16, the results of the 0 yaw cases with $7 \mathrm{~m} / \mathrm{s}$ and $15 \mathrm{~m} / \mathrm{s}$ wind speeds are compared with the NREL Phase VI experimental data (obtained from Duque et al. ${ }^{14}$ ). There is good agreement between the experimental data and the computations for case I. There is more deviation between the experimental data and computations for case III, especially on the blade upper surface. However, the comparisons are still reasonable keeping in mind that the computations are inviscid on a relatively coarse grid. The highest differences between the instantaneous and averaged $C_{P}$ distributions are observed for the $30^{\circ}$ yaw case (case II). This occurs due to the cyclic unsteady variation of blade surface pressure as the blade rotates. This is evident from the instantaneous surface pressure distributions on blade 1 (at 6 o'clock position) and blade 2 (at 12 o'clock position), as presented in Figure 14, in which the blades are at different azimuthal positions. The unsteady pressure variations also occurs for case III, however, there is no obvious cyclic variation as in case II. Consequently, the difference between the instantaneous and averaged pressure distributions is much less compared to case II, but still higher than case I which shows minimal level of cyclic variation as expected.

Figure 17 shows the time history of the thrust coefficient, $C_{T}=T /\left(\rho_{\infty}\left(\pi R^{2}\right) V_{\infty}^{2}\right)$, of time-accurate computations for all cases. In case I, $C_{T}$ starts to reach a steady state value of about 0.52 by the second revolution (corresponding to a thrust of about $2500 \mathrm{~N}$ ). For case II, a periodic oscillation of the thrust coefficient is observed around an average value of 0.425 (corresponding to a thrust of about $2000 \mathrm{~N}$ ). For case III, due to the massive separation over the blades, non-periodic oscillations are present (with an average thrust of about 4600 $\mathrm{N})$. The thrust coefficient for the yawed case is lower than the unyawed case as expected. The thrust coefficients for cases I and II are about 2.5 and 2 times higher than that in case III, respectively. Figure 18 shows time history of the force coefficients for all three cases in $\mathrm{x}$ - and z-directions (relative to the blade's initial position). In this figure, results for case I is presented for the 2nd revolution, and the results for cases II and III are for the 3rd revolution. As seen in the figure, the variations of $F_{x}$ and $F_{z}$ time histories are similar to the $C_{T}$ distributions, however the magnitudes are about 1-2 orders of magnitude smaller.

The instantaneous contours of relative velocity magnitude together with streamlines around the airfoil sections at 5 different spanwise stations for blade 2 can be seen in Figure 19 for all three computational cases. The flow is attached for both cases I and II, whereas it is massively separated for case III. This separation occurs due to the high angle of attack created by the higher wind speed than the other two cases while the rotational speed of the turbine is kept the same for all cases. Figure 20 shows the relative velocity magnitude and relative angle of attack (flow angle with respect to the x-axis) variations along the span of blade 2, obtained at the five-hole probe measurement locations as in the NREL Phase VI experiments (see Figure 4). As seen in the figure, the relative angles of attack for case III is about 2 and 3 times higher than those in cases I and II, respectively. The relative angles of attack in case II are lower and the magnitudes of relative velocity are higher than case I as expected from the velocity vector descriptions presented in Figure 8.

Schreck and Robinson ${ }^{22}$ analyzed the blade surface pressure and local inflow data from the NREL Unsteady Aerodynamics Experiment to characterize the dynamic stall vortex generated on the blade during yawed operations. It was observed that the highly three dimensional and complex vortical flow field responded systematically to alterations in the wind speed and turbine yaw angle. The changes in the flow field due to the variations in 
the wind speed and yaw angle were observed also from the results of the current study as presented in Figure 19, discussed in detail above. Leishman ${ }^{23}$ presented the challenges in modeling the unsteady aerodynamics of wind turbines, and the significance and modeling of dynamic stall for the wind turbines. Hence, the three-dimensional and time-accurate CFD simulations of the rotating wind turbine rotor blades are important and necessary in understanding the three-dimensional and complex nature of the rotor flow fields.

\section{Conclusions and Future Work}

Three different time-accurate inviscid cases have been computed for the NREL Phase VI wind turbine rotor using the 3-D, unsteady, parallel, finite volume flow solver, PUMA2, with rotating unstructured tetrahedral grids. The inviscid results show that the flow is attached for the pre-stall cases (I and II) with $0^{\circ}$ and $30^{\circ}$ yaw angles, with the latter having an asymmetrical wake structure, whereas there is massive separation over the entire blade span in the post-stall case (III), which has a higher wind speed of $15 \mathrm{~m} / \mathrm{s}$. Comparisons of sectional pressure coefficient distributions with experimental data show good agreement. Considerable spanwise pressure variations, in addition to the chordwise variations, are also observed in all three cases. These inviscid simulations with the PUMA2 code will provide a basis for the simulations of more complex cases to investigate the interactions due to atmospheric gust, turbulence and atmospheric shear layer.

Some LES simulations will also be performed for the quiescent air cases using a grid with more clustering in the wake and boundary layer regions compared to the inviscid grid. A wall function has also been implemented to the PUMA2 code, which was tested with flow over sphere simulations. ${ }^{18}$ Further modifications are being performed on PUMA2 in order to improve the code's computational efficiency for LES simulations.

These three-dimensional and time-accurate CFD results can be used for the far-field noise predictions based on the Ffowcs Williams - Hawkings method, ${ }^{9}$ which can provide a firstprinciples prediction of both the noise and the underlying turbulent flow that generates the noise, in the context of the wind turbine application.

\section{Acknowledgments}

This work was supported by the National Renewable Energy Laboratory under Subcontract No. ZAM-3-32246-01. The authors would like to thank Dr. Paul Migliore, the NREL Project Manager, for his support.

\section{References}

\footnotetext{
${ }^{1}$ Robinson, M. C., Hand, M. M., Simms, D. A., and Schreck, S. J., "Horizontal Axis Wind Turbine Aerodynamics: Three-Dimensional, Unsteady, and Separated Flow Influences," NREL/CP-500-26337. Presented at the 3rd ASME/JSME Joint Fluids Energy Conference, San Francisco, CA., 1999.

${ }^{2}$ Homicz, G. F. and George, A. R., "Broadband and Discrete Frequency Radiation from Subsonic Rotors," 1974.

${ }^{3}$ Amiet, R. K., "Acoustic Radiation from an airfoil in a Turbulent Stream," Journal of Sound and Vibration, Vol. 41, 1975, pp. 407-420.

${ }^{4}$ Amiet, R. K., "Noise Produced by Turbulent Flow into a Propeller or Helicopter Rotor," American
} 

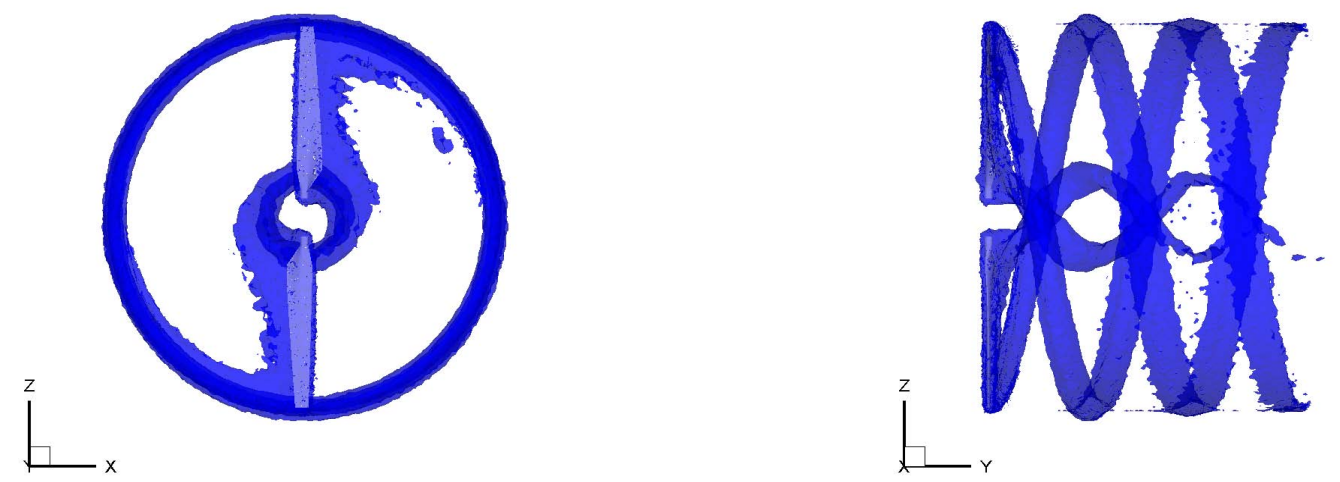

a) CASE I at $t=1.667 \mathrm{sec}$
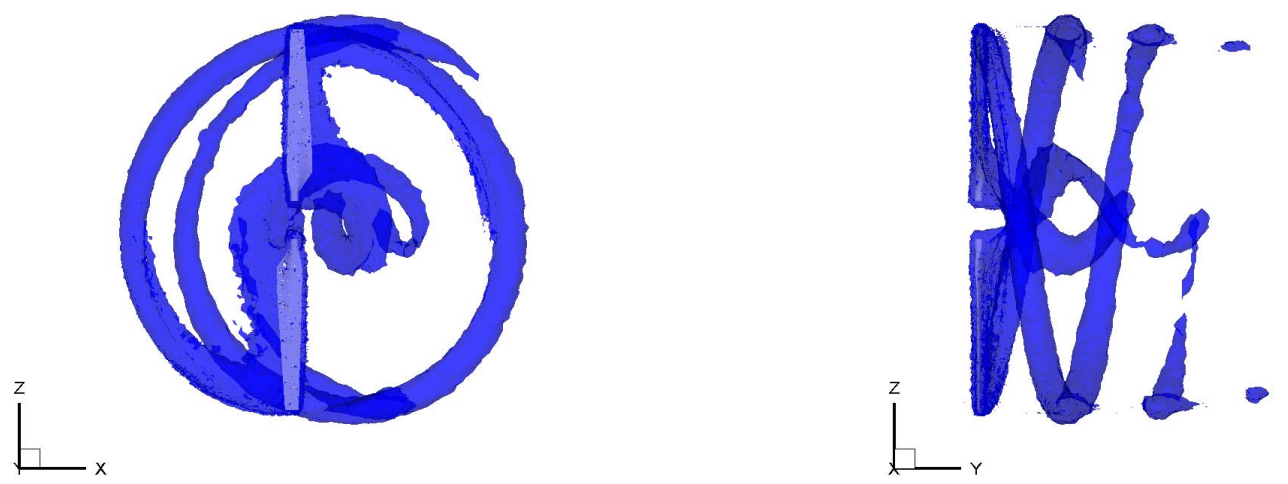

b) CASE II at $t=2.500 \mathrm{sec}$
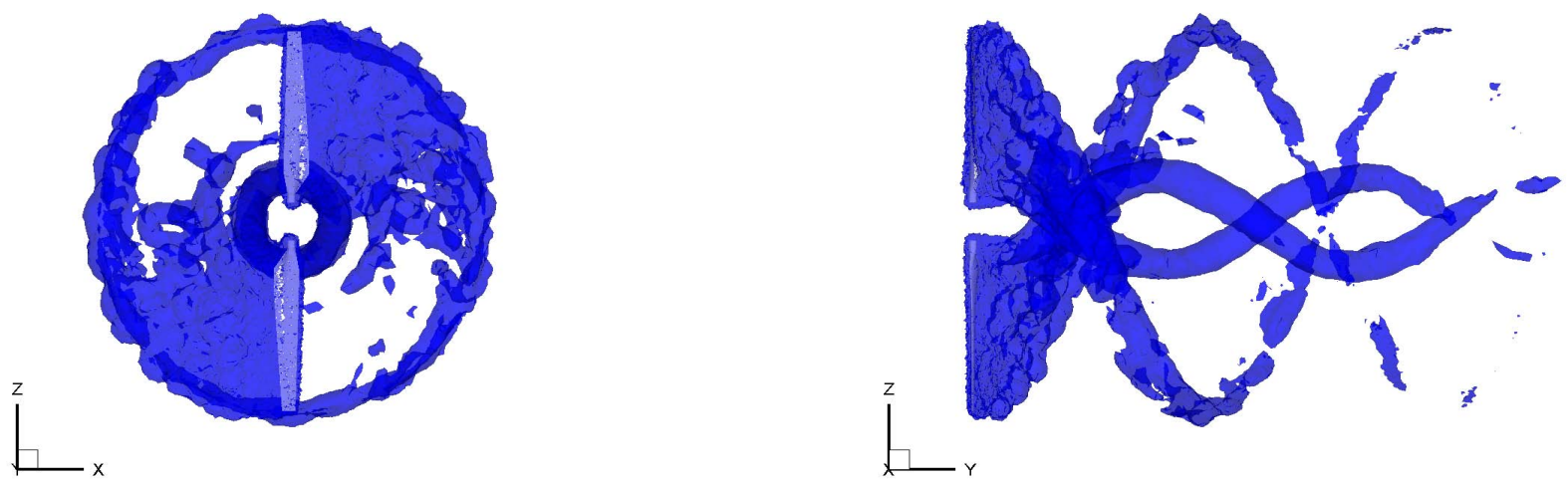

c) CASE III at $t=2.500 \mathrm{sec}$

Figure 12. Vorticity iso-surface for a) CASE I, b) CASE II, c) CASE III 

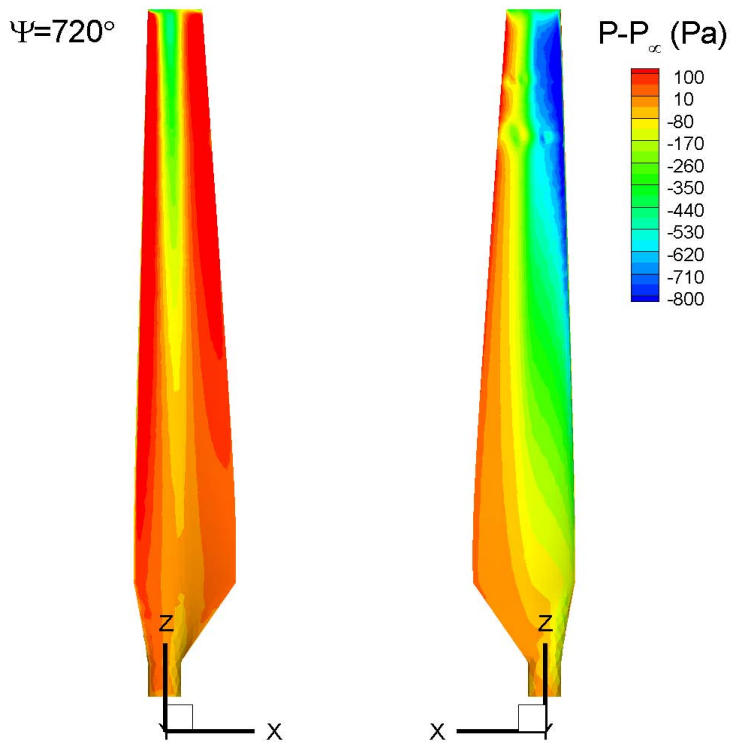

a) Blade 2
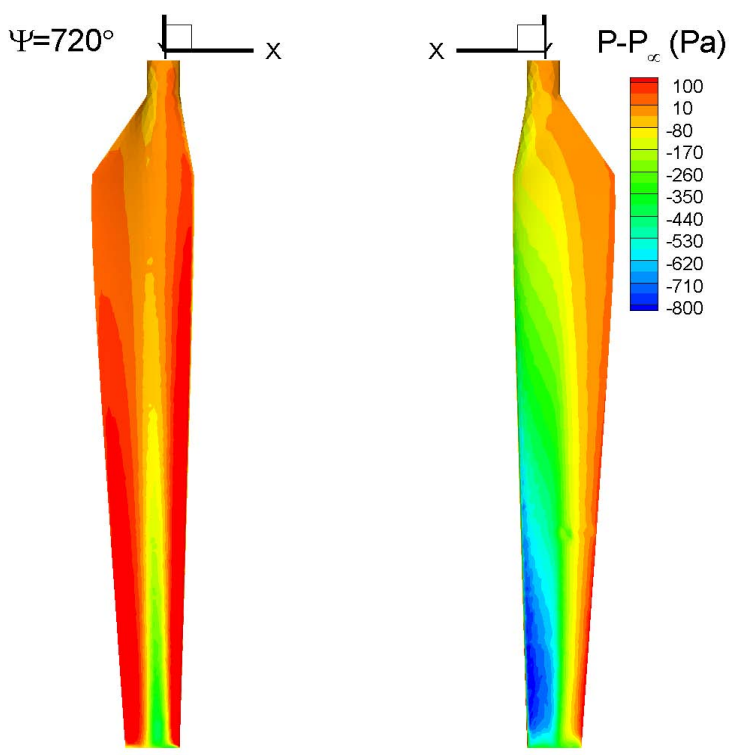

b) Blade 1

Figure 13. Gauge pressure $\left(P-P_{\infty}\right)$ contours for CASE I at $t=1.667 \sec$ (Left: lower surface, Right: upper surface). 

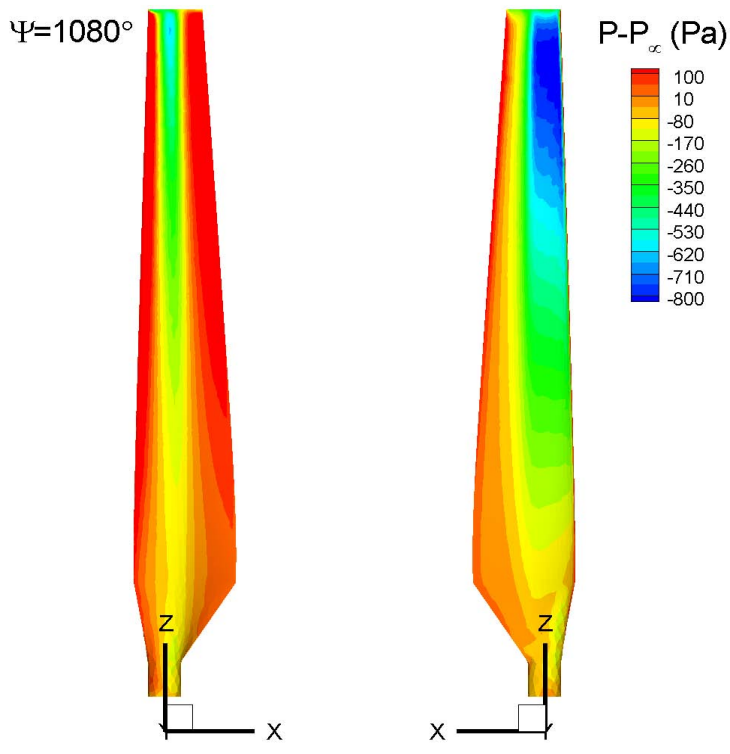

a) Blade 2
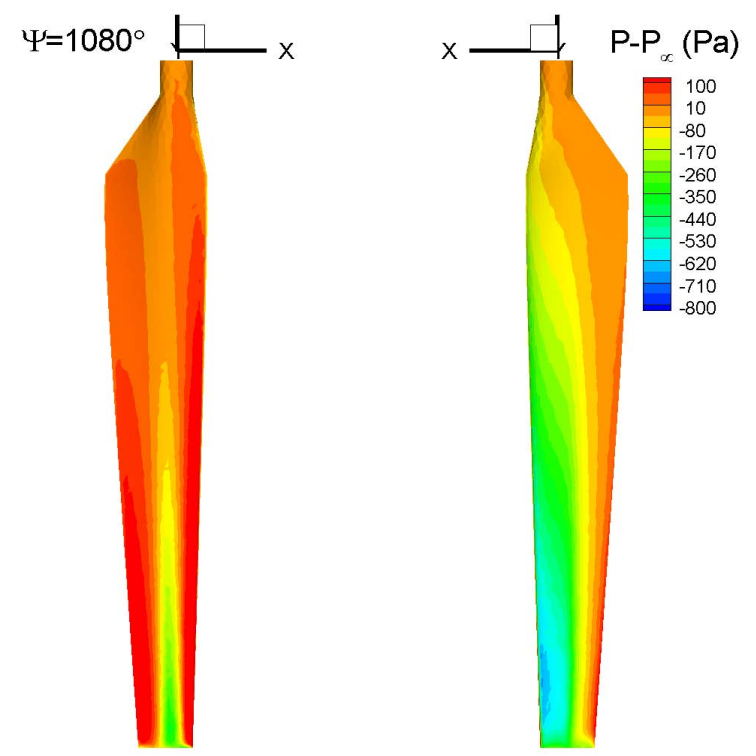

b) Blade 1

Figure 14. Gauge pressure $\left(P-P_{\infty}\right)$ contours for CASE II at $t=2.500 \sec$ (Left: lower surface, Right: upper surface). 

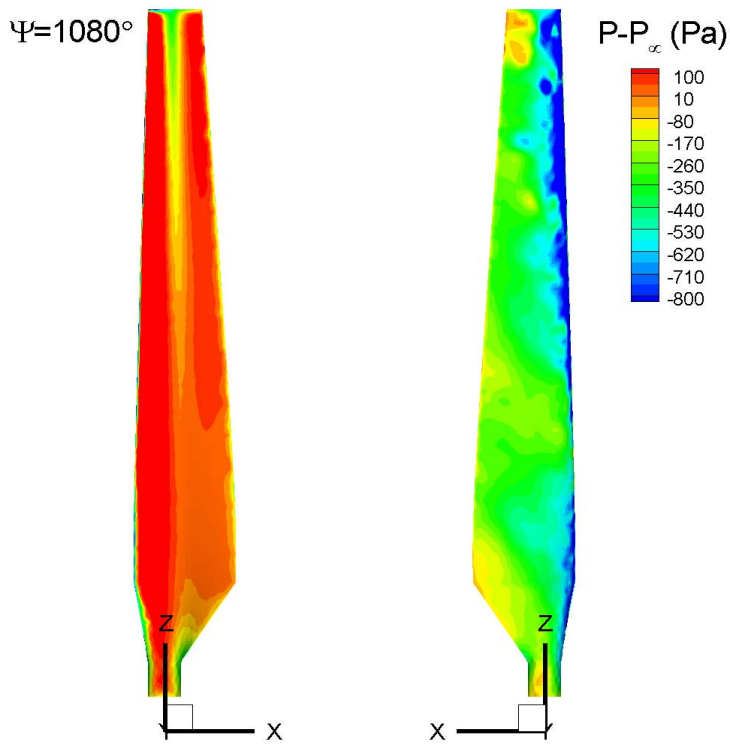

a) Blade 2
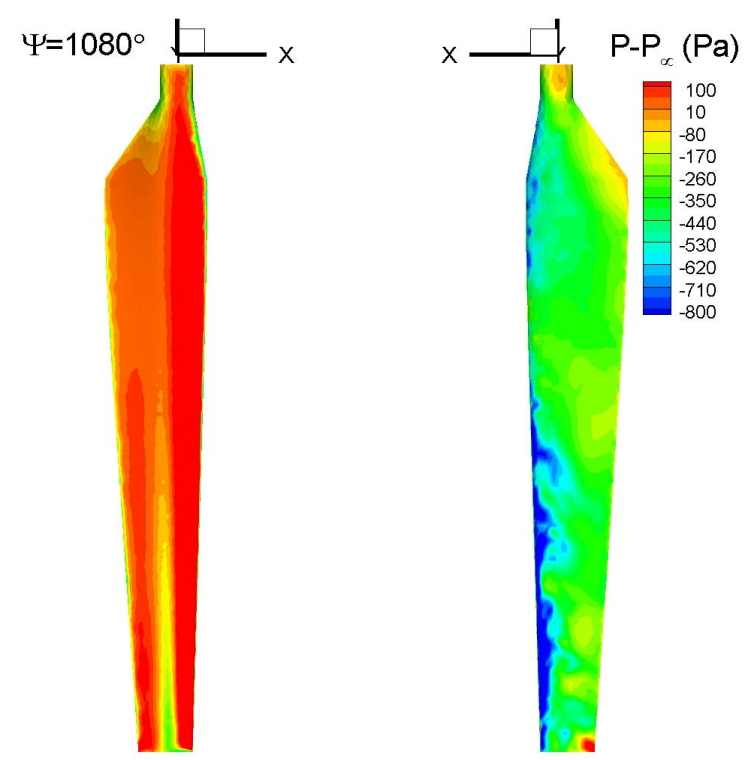

b) Blade 1

Figure 15. Gauge pressure $\left(P-P_{\infty}\right)$ contours for CASE III at $t=2.500 \sec$ (Left: lower surface, Right: upper surface). 

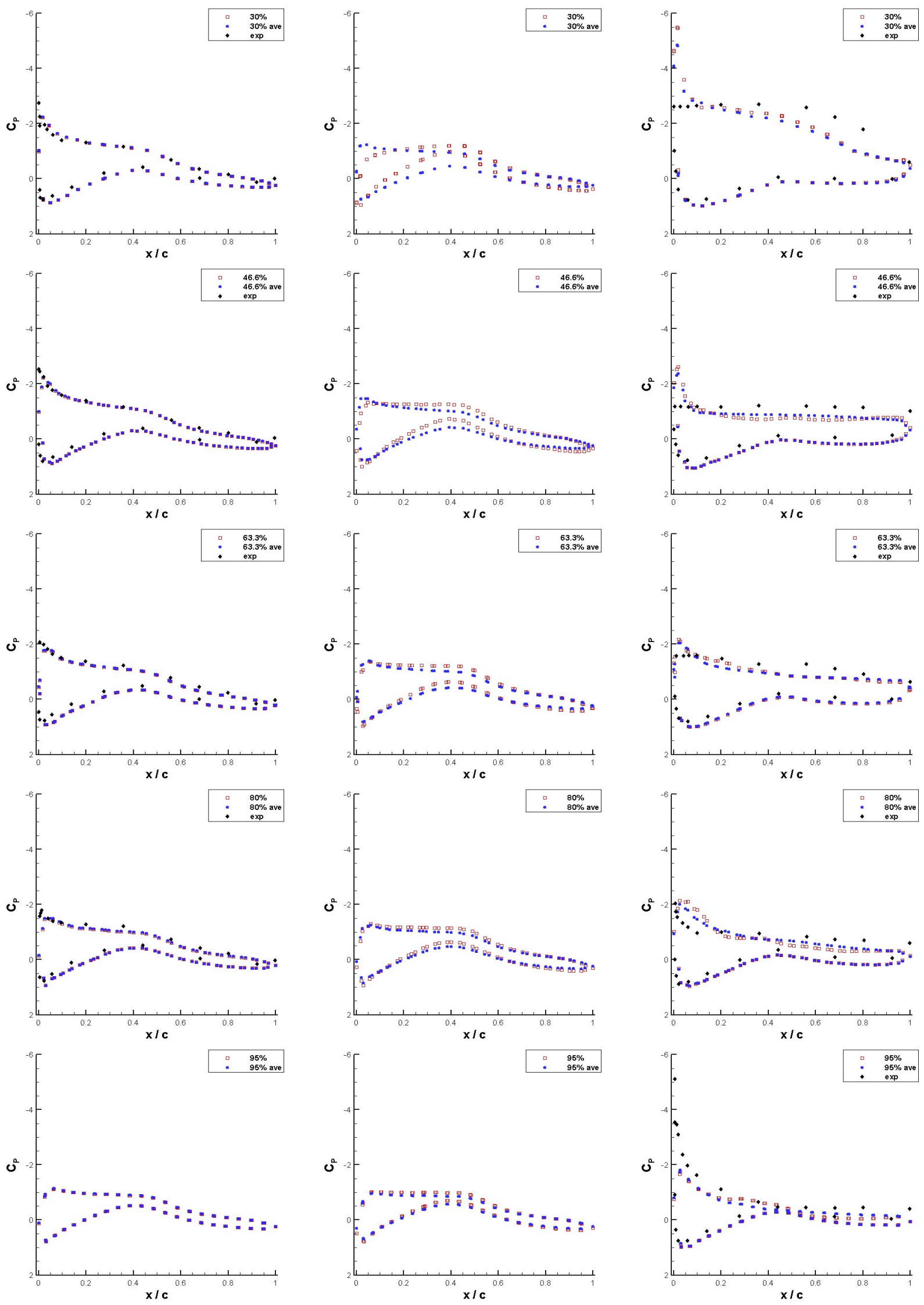

a) CASE I

b) CASE II

c) CASE III

Figure 16. Chordwise pressure coefficients at 5 spanwise blade stations for a) CASE I, b) CASE II, c) CASE III. Symbols for Instantaneous results: red square; Averaged results: blue circle, and Experimental data: black diamond. 23 


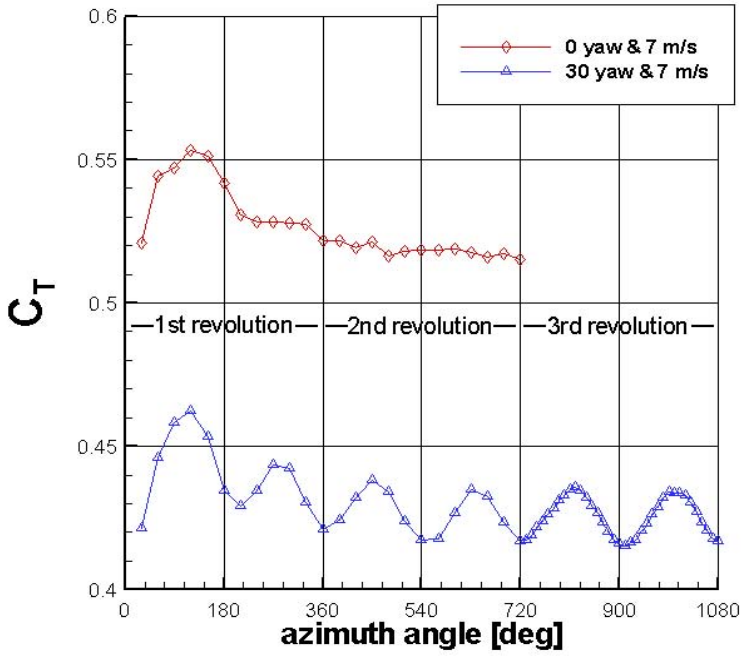

(a)

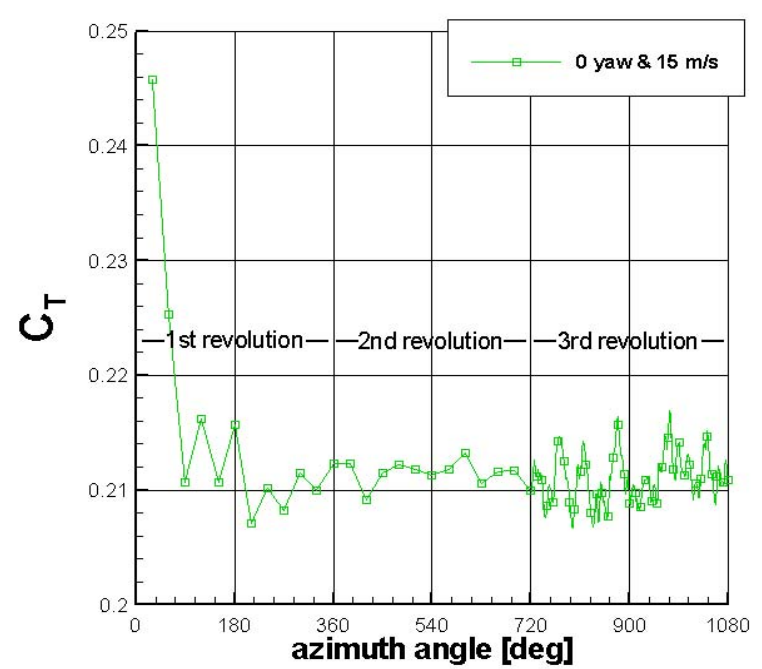

(b)

Figure 17. Time history of the thrust coefficient for a) cases I and II, and b) case III

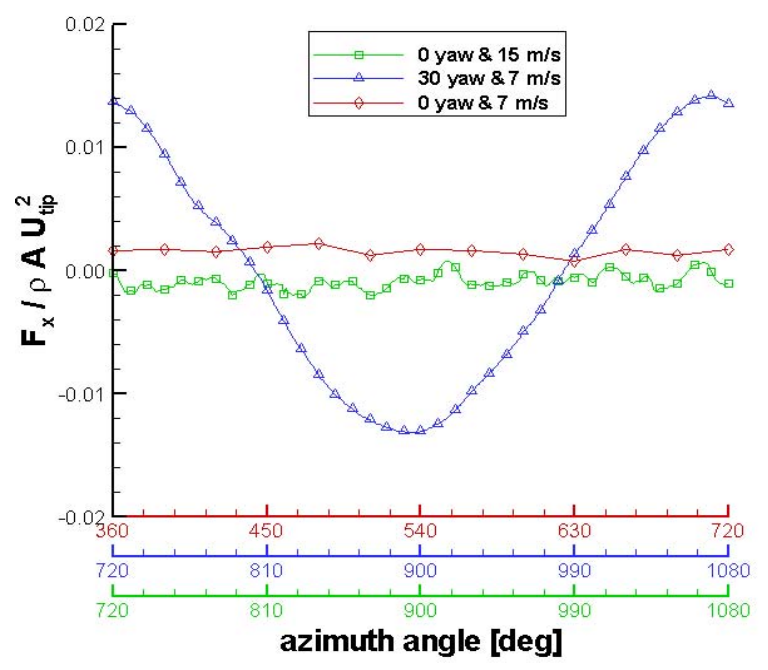

(a)

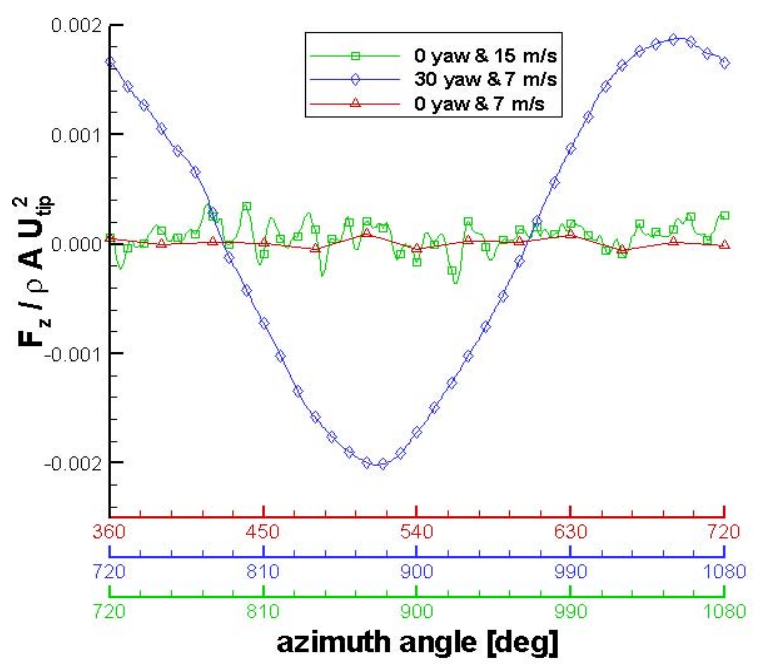

(b)

Figure 18. Time history of the force coefficients for all three cases in a) $x$-direction, and b) in z-direction (relative to the blade). 

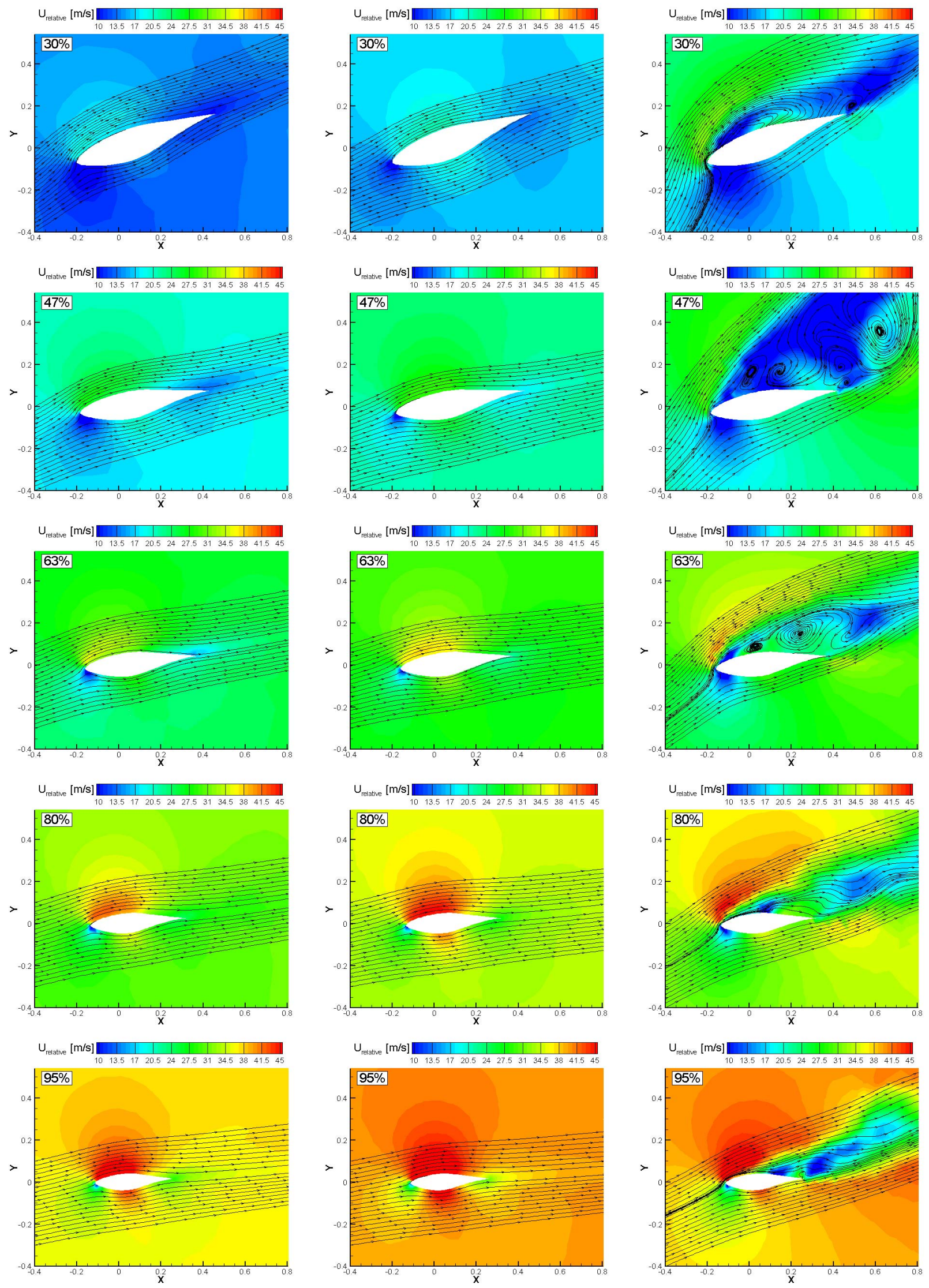

a) CASE I

b) CASE II

c) CASE III

Figure 19. Relative velocity magnitude contours with streamlines around the airfoil sections at 5 spanwise blade stations for a) CASE I at $\mathrm{t}=1.667 \mathrm{sec}, \mathrm{b}) \mathrm{CASE}$ II, and c) CASE III at $\mathrm{t}=2.500 \mathrm{sec}$ 


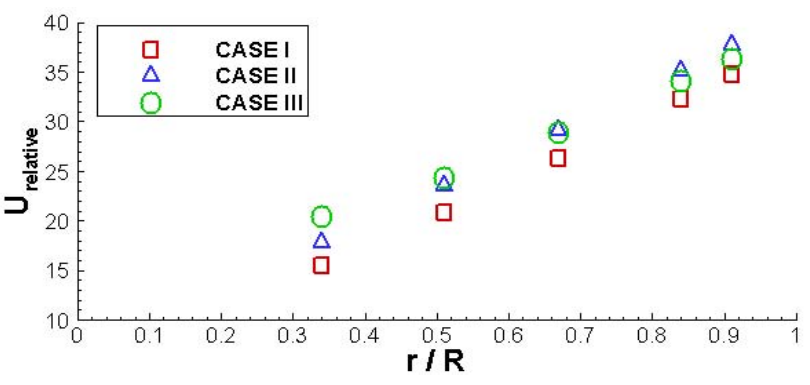

a) Relative velocity magnitude

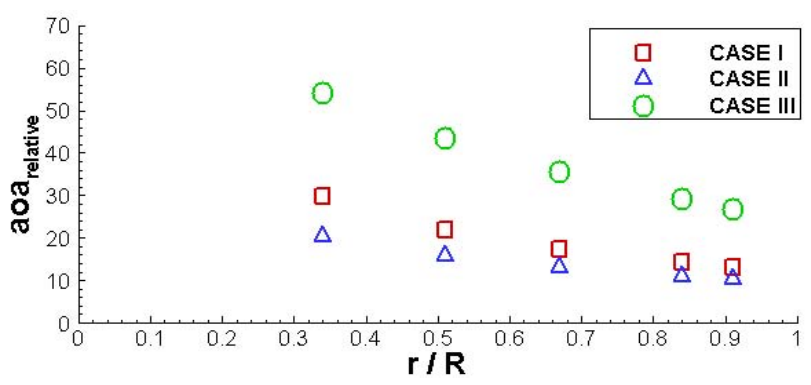

b) Relative angle of attack

Figure 20. Instantaneous relative a) velocity magnitude and b) angle of attack distributions at five spanwise stations along blade 2 , for case $\mathrm{I}$ at $\mathrm{t}=1.667 \mathrm{sec}$, and for cases II and III at $\mathrm{t}=\mathbf{2 . 5 0 0}$ sec.

Institute of Aeronautics and Astronautics Journal, Vol. 15, 1977, pp. 307-308.

${ }^{5}$ Grosveld, F. W., "Prediction of Broadband Noise from Horizontal Axis Wind Turbines," Journal of Propulsion and Power, Vol. 1, 1985.

${ }^{6}$ Brooks, T. F., Pope, D. S., and Marcolini, M. A., "Airfoil Self-Noise and Prediction," NASA Reference Publication 1219, 1989.

${ }^{7}$ Corfeld, K., Strawn, R., and Long, L. N., "A Computational Aerodynamics Simulation of a Martian Rotorcraft," Journal of the American Helicopter Society, Vol. 49, No. 3, July 2004.

${ }^{8}$ Modi, A., Sezer-Uzol, N., Long, L. N., and Plassmann, P. E., "Scalable Computational Steering for Visualization and Control of Large-Scale Fluid Dynamics Simulations," Journal of Aircraft, Vol. 42, No. 4, 2005, pp. 963-975.

${ }^{9}$ Ffowcs Williams, J. E. and Hawkings, D. L., "Sound generation by turbulence and surfaces in arbitrary motion," Philosophical Transactions of the Royal Society of London, Series A, Vol. 264, 1969, pp. 321-342.

${ }^{10}$ Morris, P. J., Long, L. N., and Brentner, K. S., "An Aeroacoustic Analysis of Wind Turbines," AIAA2004-1184, 42nd AIAA Aerospace Sciences Meeting and Exhibit, Reno, Nevada, January 5-8 2004.

${ }^{11}$ Chyczewski, T., Long, L. N., and Morris, P., "Numerical Study of Nozzle Exit Condition Effects on Jet Development," AIAA Journal, Vol. Vol. 36, No. No. 6, June 1998.

${ }^{12}$ Benjanirat, S., Sankar, L. N., and Xu, G., "Evaluation of Turbulence Models for the Prediction of Wind Turbine Aerodynamics," AIAA 2003-517, 41st AIAA Aerospace Sciences Meeting and Exhibit, Reno, Nevada, January 6-9 2003.

${ }^{13}$ Madsen, H. A., Sorensen, N. N., and Schreck, S., "Yaw Aerodynamics Analyzed with Three Codes in Comparison with Experiment," AIAA 2003-519, 41st AIAA Aerospace Sciences Meeting and Exhibit, Reno, Nevada, January 6-9 2003.

${ }^{14}$ Duque, E. P. N., Burklund, M. D., and Johnson, W., "Navier-Stokes and Comprehensive Analysis Performance Predictions of the NREL Phase VI Experiment," AIAA 2003-355, 41st AIAA Aerospace Sciences Meeting and Exhibit, Reno, Nevada, January 6-9 2003.

${ }^{15}$ Iida, M., Fleig, O., Arakawa, C., and Shimooka, M., "Wind Turbine Flow and Noise Prediction by Large Eddy Simulation," AIAA 2005-1188, 43rd AIAA Aerospace Sciences Meeting and Exhibit, Reno, Nevada, January 10-13 2005.

${ }^{16}$ Tongchitpakdee, C., Benjanirat, S., and Sankar, L. N., "Numerical Simulation of the Aerodynamics of Horizontal Axis Wind Turbines Under Yawed Flow Conditions," AIAA 2005-773, 43rd AIAA Aerospace Sciences Meeting and Exhibit, Reno, Nevada, January 10-13 2005.

${ }^{17}$ Souliez, F. J., "Parallel Methods for Computing Unsteady Separated Flows around Complex Geometries," Ph.D. Thesis, Penn State Univ., August 2002.

${ }^{18}$ Jindal, S., Long, L. N., Plassmann, P. E., and Sezer-Uzol, N., "Large Eddy Simulations Around A Sphere Using Unstructured Grids," AIAA 2004-2228, 34th AIAA Fluid Dynamics Conference and Exhibit, Portland, Oregon, June 28 - July 12004.

${ }^{19}$ Sagaut, P., Large Eddy Simulations for Incompressible Flows, Springer, Chattilon, France, 2002. 
${ }^{20}$ Giguere, P. and Selig, M. S., "Design of a Tapared and Twisted Blade for the NREL Combined Experiment Rotor," Nrel/sr-500-26173, NREL, April 1999.

${ }^{21}$ Hand, M., Simms, D., Fingersh, L., Jager, D., Cotrell, J., Schreck, S., and Larwood, S., "Unsteady Aerodynamics Experiment Phase VI: Wind Tunnel Test Configurations and Available Data Campaigns," Nrel/tp-500-29955, NREL, December 2001.

${ }^{22}$ Schreck, S. and Robinson, M., "Blade Three-dimensional Dynamic Stall Response to Wind Turbine Operating Condition," FEDSM2003-45362, Proceedings of ASME FEDSM'03. 4th ASME-JSME Joint Fluids Engineering Conference, Honolulu, Hawaii, USA, July 6-10 2003.

${ }^{23}$ Leishman, J. G., "Challenges in Modeling the Unsteady Aerodynamics of Wind Turbines," AIAA2002-0037, 21st ASME Wind Energy Symposium and 40th AIAA Aerospace Sciences Meeting, Reno, NV, January 14-17 2002. 